\title{
A novel approach to oxoisoaporphine alkaloids via regioselective metalation of alkoxy isoquinolines
}

\author{
Benedikt C. Melzer and Franz Bracher ${ }^{*}$
}

\author{
Full Research Paper \\ Address: \\ Department für Pharmazie - Zentrum für Pharmaforschung, \\ Ludwig-Maximilians Universität München, Butenandtstr. 5-13, \\ D-81377 Munich, Germany \\ Email: \\ Franz Bracher ${ }^{*}$ - Franz.Bracher@cup.uni-muenchen.de \\ * Corresponding author \\ Keywords: \\ directed ortho/remote metalation; Eaton's reagent; isoquinolines; \\ Suzuki cross-coupling
}

Beilstein J. Org. Chem. 2017, 13, 1564-1571.

doi:10.3762/bjoc. 13.156

Received: 24 May 2017

Accepted: 28 July 2017

Published: 08 August 2017

Associate Editor: D. J. Dixon

(C) 2017 Melzer and Bracher; licensee Beilstein-Institut.

License and terms: see end of document.

\begin{abstract}
Oxoisoaporphine alkaloids are conveniently prepared via direct ring metalation of alkoxy-substituted isoquinolines at C-1, followed by reaction with iodine. Subsequent Suzuki cross-coupling of the resulting 1-iodoisoquinolines to methyl 2-(isoquinolin-1yl)benzoates and intramolecular acylation of the corresponding carboxylic acids with Eaton's reagent afforded five alkaloids of the oxoisoaporphine type. The yield of the cyclization step strongly depends on the electrophilic properties of ring B. An alternative cyclization protocol via directed remote metalation of ester and amide intermediates was investigated thoroughly, but found to be not feasible. Two of the alkaloids showed strong cytotoxicity against the HL-60 tumor cell line.
\end{abstract}

\section{Introduction}

Benzylisoquinoline alkaloids represent a very large group of plant secondary metabolites, which includes about 2,500 known structures. Besides simple benzylisoquinolines, more complex tetracyclic ring systems like aporphines, protoberberines, cularines, pavines, as well as pentacyclic morphinane-type alkaloids belong to this class. Biosynthetically, all of these chemotypes are derived from the 1-benzyltetrahydroisoquinoline $(S)$-norcoclaurine. The structures, biosynthesis and pharmacology of benzylisoquinoline alkaloids have been reviewed recently by Hagel and Facchini [1].

The subgroup of aporphinoid alkaloids [2] consists of the aporphines and oxoaporphines (e.g., liriodenine (1)), as well as several truncated chemotypes like aristolactams and azafluoranthenes, and is of considerable pharmacological interest due to the significant cytotoxicity of numerous representatives [3]. A unique subclass of the aporphinoid alkaloids are the oxoisoaporphines ( $7 H$-dibenzo[de, $h]$ quinolin-7-ones, e.g., menisporphine, (2)), which at the first glance appear to be not derived from 1-benzyltetrahydroisoquinoline intermediates, albeit a hypothesis of Kunitomo postulates a biosynthesis from a benzylisoquinoline precursor involving a rearrangement (Figure 1) [4].

Menisporphine (2), first isolated from Menispermum dauricum DC [4], shows antiangiogenic activity. Some, partly synthetic, oxoisoaporphine-like analogues were found to have strong 


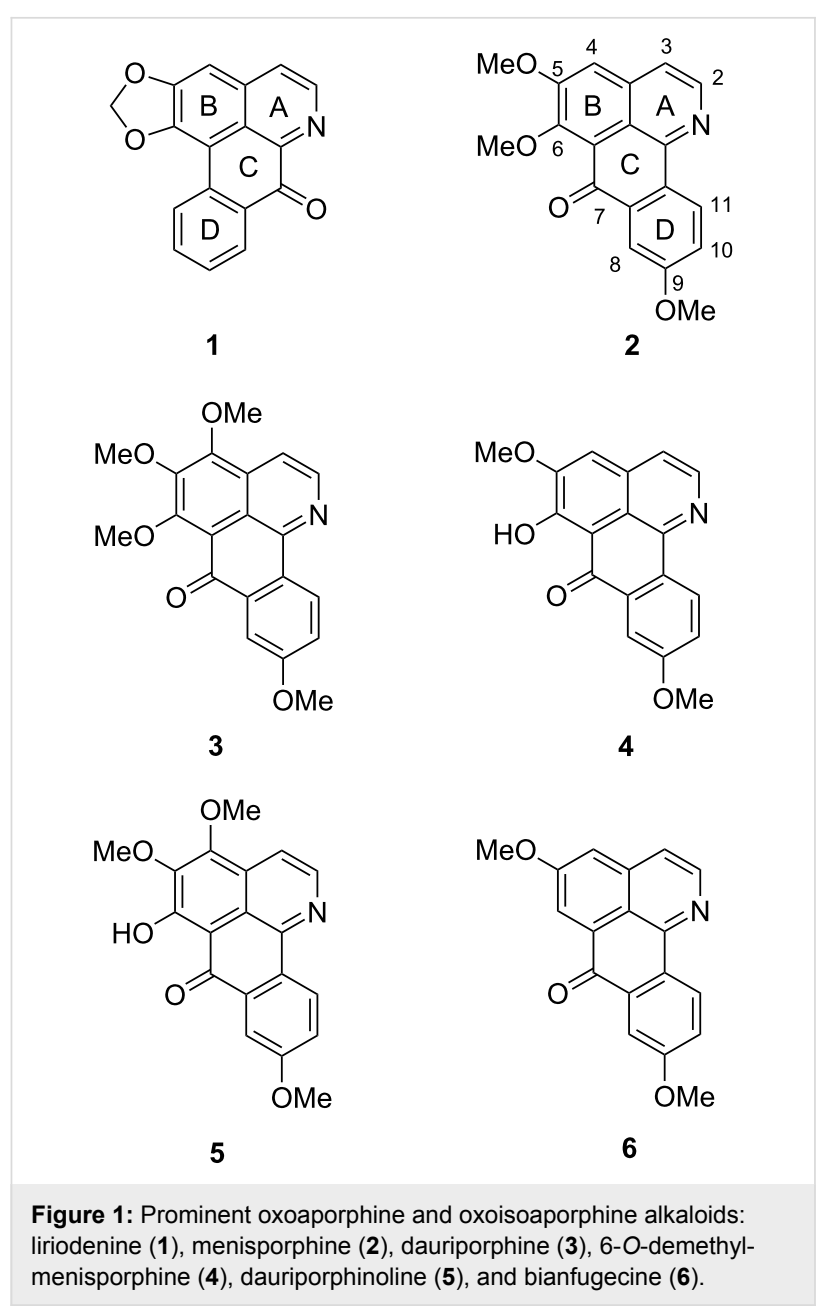

DNA binding affinity and therefore high cytotoxicity [5] as well as antiplasmodial activity [6]. Besides menisporphine (2), the related oxoisoaporphine alkaloids dauriporphine (3), 6-Odemethylmenisporphine (4), dauriporphinoline (5) and bianfugecine (6) were isolated from Menispermum dauricum DC, among a few other plants $[1,7,8]$.

A number of approaches to the oxoaporphine ring system has been published, typically involving the synthesis of 1-benzyl/ 1-benzoylisoquinoline intermediates, followed by cyclization under intramolecular biaryl synthesis, utilizing either photochemical [9-13], radical [14] or Pd-catalyzed $[15,16]$ reactions.

In contrast, only minute work has been published on the synthesis of oxoisoaporphines. The approaches are mainly based on Kunitomo's total syntheses of menisporphine (2) [7] and dauriporphine (3) [17], which start with the synthesis of 1-(2bromoaryl)isoquinolines using Bischler-Napieralski chemistry, followed by tedious replacement of the bromine substituent by cyanide (for modern variants, see ref. [18,19]), and subsequent conversion to a carboxylate and Friedel-Crafts-type cyclization using polyphosphoric acid (Scheme 1). In the course of this cyclization, the methoxy group at C-6 is typically hydrolized to the phenol, subsequent $O$-methylation gives the 6-methoxy derivatives menisporphine (2) and dauriporphine (3). Recently, Zhang et al. [20] described an alternative approach starting from an isoquinoline bearing an ester group at $\mathrm{C}-8$. In a photoredoxcatalyzed direct $\mathrm{C}-\mathrm{H}$ arylation a 4-methoxyphenyl residue from a methoxyphenyldiazonium salt was introduced at $\mathrm{C}-1$, and after ester hydrolysis intramolecular Friedel-Crafts acylation afforded menisporphine (2).

In continuation of our recent work on the synthesis of polycyclic aromatic alkaloids like pyridoacridine, benzylisoquinoline-type and oxoaporphine alkaloids using direct ring metalations of heterocycles as vital step [13,21] we intended to develop a novel and more flexible access to oxoisoaporphine alkaloids. Again we were inspired by Knochel's reports on the direct metalation of isoquinoline [22] and 6,7-dimethoxyisoquinoline [23] as well as by our own results for the metalation of various alkoxyisoquinolines [13] at C-1 with the Knochel-Hauser base TMPMgCl-LiCl. Transmetalation of the intermediate organomagnesium species with $\mathrm{ZnCl}_{2}$ should lead to at $\mathrm{C}-1$ zincated isoquinolines, which could undergo Negishi cross-coupling reactions with appropriately substituted methyl 2-bromobenzoates to give methyl 2-(isoquinolin-1yl)benzoates. These would again open an access to oxoisoaporphine alkaloids via intramolecular acylation following Kunitomo's strategy. Main advantage of this approach should be that the laborious introduction of the carboxy residue at a late stage of the total synthesis is circumvented. Alternatively, quenching of the 1-magnesiated alkoxyisoquinolines with iodine should lead to 1-iodoisoquinolines, which were expected to be versatile substrates for Suzuki cross-coupling reactions with appropriate phenylboronic acids to gain methyl 2-(isoquinolin-1-yl)benzoates as the central intermediates (Scheme 1).

\section{Results and Discussion}

As we reported previously, metalation of 6,7-dimethoxyisoquinoline (7a) and 5,6,7-trimethoxyisoquinoline (7b) with 1.5 equivalents of the Knochel-Hauser base (TMPMgCl$\cdot \mathrm{LiCl})$ exclusively occurs at C-1. Trapping with appropriate benzaldehydes opened an access to benzylisoquinoline and oxoaporphine-type alkaloids [13]. Here we describe the extension of this approach to the synthesis of oxoisoaporphines.

By using our modification (1.5 equivalents of TMPMgCl $\cdot \mathrm{LiCl}$ over $4 \mathrm{~h}$ at room temperature) [13] of Knochel's [23] protocol for the metalation of isoquinolines, the alkoxy-substituted isoquinolines $\mathbf{7 a}, \mathbf{b}$ were metalated at $\mathrm{C}-1$, as shown before, and this method could conveniently be extended to 6-methoxyiso- 


\section{previous approach:}<smiles>[R]c1c(CCNC(=O)c2ccc(OC)cc2Br)ccc(OC)c1OC</smiles><smiles>[R]c1c(OC)c(OC)cc2c(-c3ccc(OC)cc3OC)nccc12</smiles><smiles>[R]c1c(OC)c(O)c2c3c(nccc13)-c1ccc(OC)cc1C2=O</smiles>

$\mathrm{R}=\mathrm{H}$ or $\mathrm{OMe}$

aspired new approach:<smiles></smiles>

$\mathrm{R}^{1}, \mathrm{R}^{2}=\mathrm{H}$ or $\mathrm{OMe}$
1) $\mathrm{ZnCl}_{2}$

2) $\mathrm{Ar}-\mathrm{Br}$

Negishi

cross-

or

1) $I_{2}$

2) Ar-Bpin

Suzuki

cross-

coupling

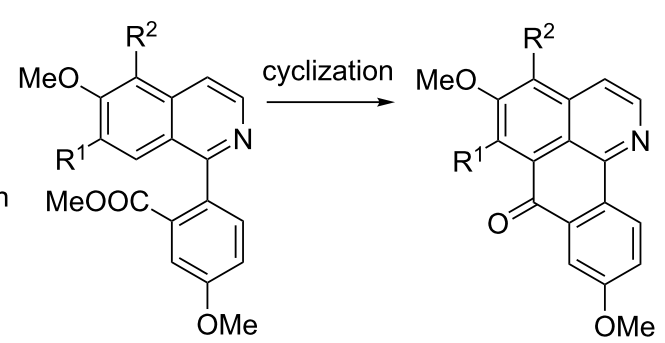

Scheme 1: Previously reported $[7,17]$ and new approach to oxoisoaporphine alkaloids.

quinoline (7c). Unfortunately, transmetalation with $\mathrm{ZnCl}_{2}$ at $0{ }^{\circ} \mathrm{C}$ followed by palladium-catalyzed ( $5 \mathrm{~mol} \% \mathrm{Pd}(\mathrm{dba})_{2} /$ $10 \mathrm{~mol} \% \mathrm{P}(2 \text {-furyl })_{3}$ or $1 \mathrm{~mol} \% \mathrm{Pd}_{2}(\mathrm{dba})_{3} / 2 \mathrm{~mol} \%$ RuPhos $)$ Negishi cross-coupling reaction with methyl 2-bromo-5methoxybenzoate did not lead to the expected methyl 2-(isoquinolin-1-yl)benzoates $\mathbf{1 0}$ after up to $72 \mathrm{~h}$ at room temperature or $60{ }^{\circ} \mathrm{C}$ [22]. Starting materials were recovered almost quantitatively. However, quenching with iodine gave the 1-iodoisoquinolines 8a [23], 8b, and $\mathbf{8 c}$ in good yields (53-67\%, Scheme 2).

For the introduction of ring $\mathrm{D}$ of the oxoisoaporphine alkaloids one common building block, (4-methoxy-2-(methoxycarbonyl)phenyl)boronic acid pinacol ester (9) [24], could be applied, since the alkaloids of interest all bear the methoxy group at C-9. Suzuki cross-coupling reaction of the iodinated isoquinolines $\mathbf{8 a}-\mathbf{c}$ with this boronate under $\mathrm{Pd}\left(\mathrm{PPh}_{3}\right)_{4}$ catalysis gave the desired 1-arylisoquinolines $\mathbf{1 0 a}-\mathbf{c}$ in moderate to good isolated yields (65-77\%, Scheme 3$)$. Up to $20 \%$ of the starting materials 8a-c were typically recovered, but all attempts to achieve complete conversion (longer reaction times, other catalysts and bases) were in vain.

The esters 10a-c are valuable intermediates for the further conversion to the target oxoisoaporphines, and in previous protocols $[7,17]$ the esters were typically converted into the corresponding carboxylic acids, and then cyclized using polyphosphoric acid. Previously we found that esters can directly be sub-<smiles>[R]c1cc2cnccc2c([R])c1OC</smiles>

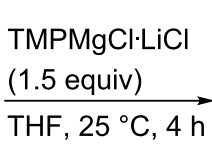

$7 a R^{1}=O M e, R^{2}=H$

$7 b R^{1}=O M e, R^{2}=O M e$

7c $R^{1}=H, R^{2}=H$<smiles>[R]c1cc2c(C)nccc2c([N+]([O-])Cl)c1OC</smiles><smiles>[R]c1cc2c(I)nccc2c([R])c1OC</smiles>

$8 a R^{1}=O M e, R^{2}=H(67 \%)$

8b $\mathrm{R}^{1}=\mathrm{OMe}, \mathrm{R}^{2}=\mathrm{OMe}(53 \%)$

$8 c R^{1}=H, R^{2}=H(59 \%)$ 


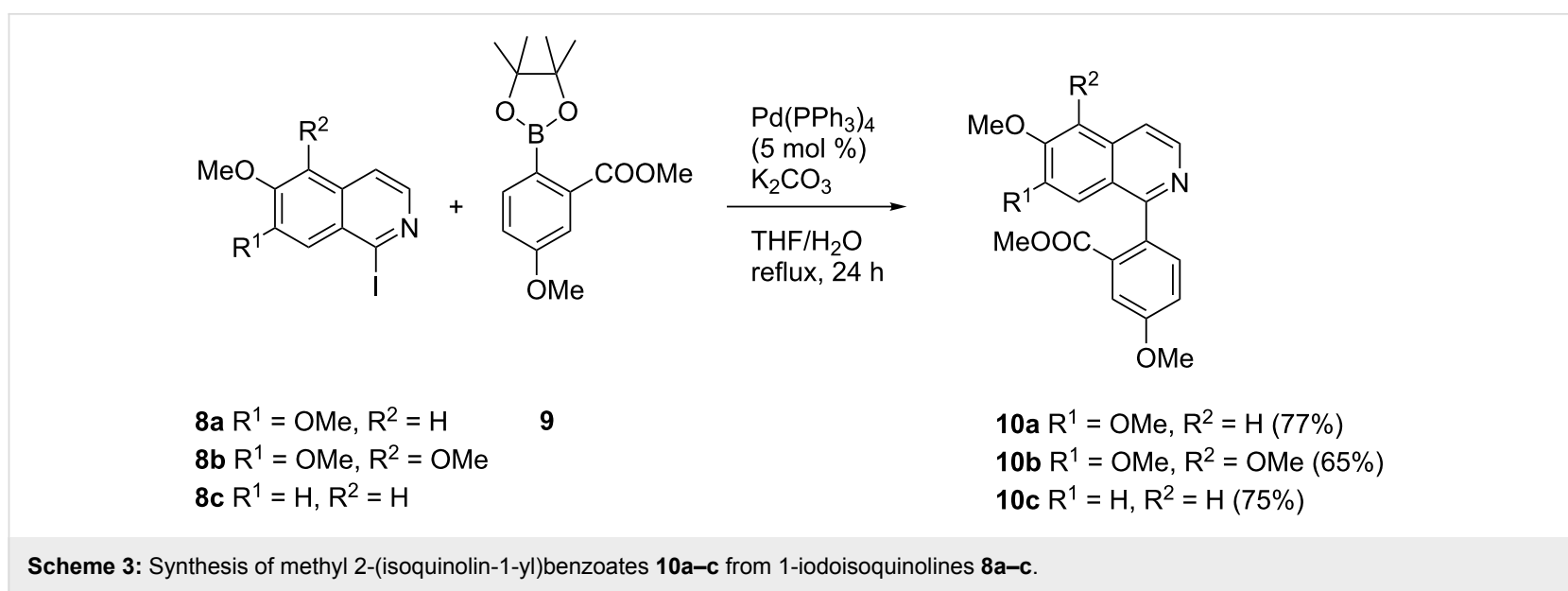

jected to this type of intramolecular Friedel-Crafts-type acylations, and trifluoromethanesulfonic acid [25] is superior to polyphosphoric acid $[26,27]$ for the synthesis of polycyclic ketones. Unfortunately, direct cyclization of esters 10a-c using this reagent failed completely, despite numerous variations of the reaction conditions. As an alternative reagent for the acylation of arenes with esters Eaton's reagent (phosphorus pentoxide, $7.7 \mathrm{wt} \%$ in methanesulfonic acid) has been described in the literature $[28,29]$. Eaton's reagent has advantages over polyphosphoric acid as it is an easy to handle, non-viscous and freely measurable liquid, and therefore more suitable for small-scale synthesis. However, attempted direct cyclization of ester 10a with Eaton's reagent to menisporphine (2) failed. Consequently, we had to come back to Kunitomo's approach $[7,17]$ via carboxylate intermediates. Carboxylic acid 11a was conveniently obtained by hydrolysis of the methyl ester 10a with concentrated hydrochloric acid. The crude carboxylic acid 11a underwent cyclization to 6-O-demethylmenisporphine (4) with Eaton's reagent in 45\% yield over both steps (Scheme 4). In accordance with Kunitomo's observations [7,17], we also observed demethylation of the methoxy group at C-6. Dauripor- phinoline (5) was synthesized in 58\% yield using the same protocol starting from the methyl ester $\mathbf{1 0 b}$, once again under hydrolysis of the 6-methoxy group.

In order to explore the scope of this new cyclization methodology, we further investigated the synthesis of the alkaloid bianfugecine (6, Scheme 4), which contains only one methoxy group at ring B. Until now, only one partial synthesis of this alkaloid is described in the literature. Kunitomo et al. [30] obtained alkaloid 6 by hydrogenolytic demethoxylation of alkaloid menisporphine (2) with $\mathrm{H}_{2} / \mathrm{PtO}_{2}$ in acetic acid. Unfortunately, upon cyclization of the carboxylic acid 11c, obtained by acidic hydrolysis of ester 10c, with Eaton's reagent alkaloid 6 could be isolated in only very poor yield $(7 \%)$. Other established cyclization methods starting from methyl ester 10c were tested in order to increase the yield. As described above, attempted direct intramolecular Friedel-Crafts-type cyclization of 10c catalyzed by trifluoromethanesulfonic acid [25] failed completely. Also, generation of an acid chloride from 11c with thionyl chloride, followed by the reaction with $\mathrm{AlCl}_{3}$ did not even give traces of bianfugecine (6).<smiles>[R]c1cc2c(-c3ccc(OC)cc3OC)nccc2c([R])c1OC</smiles>

$$
\begin{aligned}
& 10 a R^{1}=O M e, R^{2}=H \\
& 10 b R^{1}=O M e, R^{2}=O M e \\
& 10 c R^{1}=H, R^{2}=H
\end{aligned}
$$<smiles>[R]c1cc2c(-c3ccc(OC)cc3C(=O)O)nccc2c([R])c1OC</smiles>

$$
\begin{aligned}
& \text { 11a } R^{1}=O M e, R^{2}=H \\
& 11 b R^{1}=O M e, R^{2}=O M e \\
& 11 c R^{1}=H, R^{2}=H
\end{aligned}
$$<smiles>[R]c1c(OC)c([R])c2ccnc3c2c1C(=O)c1cc(OC)ccc1-3</smiles>

$$
\begin{aligned}
& 4 \mathrm{R}^{1}=\mathrm{OH}, \mathrm{R}^{2}=\mathrm{H}(45 \%) \\
& 5 \mathrm{R}^{1}=\mathrm{OH}, \mathrm{R}^{2}=\mathrm{OMe}(58 \%) \\
& 6 \mathrm{R}^{1}=\mathrm{H}, \mathrm{R}^{2}=\mathrm{H}(7 \%)
\end{aligned}
$$


Taken all of these results together, intramolecular Friedel-Crafts-type cyclization aimed at the construction of the oxoisoaporphine scaffold is a very challenging conversion, and the electronic properties of the ring to be attacked (ring B) strongly determine the outcome of this reaction.

Inspired by a report from the Snieckus group [31] on the application of the directed remote metalation (DreM) methodology for generation of carbanionic Friedel-Crafts equivalents (generating acridones from diarylamine carboxamides), we converted methyl ester 10c into the corresponding diethyl amide 12. For this purpose, ester 10c was reacted in a Weinreb amidation [32] with a mixture of trimethylaluminium and diethylamine to give the amide 12 in $31 \%$ yield (Scheme 5). The diethyl amide moiety was designated to promote a directed remote metalation by lithium diisopropylamide (LDA) at C-8 of the isoquinoline ring, which should be followed by an intramolecular trapping of the amide group to give the oxoisoaporphine bianfugecine $(\mathbf{6}$, Scheme 5). However, only starting material 12 was recovered from this reaction.

A $\mathrm{D}_{2} \mathrm{O}$ quenching experiment after the metalation period (4 equiv LDA, $1 \mathrm{~h}, 25^{\circ} \mathrm{C}$ ) was performed in order to identify the position(s) of ring metalation of $\mathbf{1 2}$. In recovered (about $80 \%$ ) educt, deuterium incorporation (about $40 \%$; calculated from integrals of the ${ }^{1} \mathrm{H}$ NMR spectrum) was observed exclu- sively at C-6 of the benzamide moiety (Scheme 6). It is known for decades [33] that cooperative effects of directing groups lead to directed ortho-metalation (DoM) at their common orthoposition (C-6 in this case, located ortho to both the amide and the methoxy group). Nevertheless, under reversible metalation conditions, typically existing when amide bases like LDA are employed, kinetically controlled DoM can be followed by an equilibration to give a thermodynamically controlled DreM product [34]. This has been demonstrated by Tilly et al. [35] in the synthesis of fluorenones by treatment of $N, N$-dialkyl biphenyl-2-carboxamides with LDA. In our case, however, initial metalation at C- 6 of the benzamide moiety was not followed by an equilibration giving the desired 8'-metalated intermediate (which in turn should be trapped by the amide group to give the tetracyclic ketone 6). Probably, the DreM at C-8' is prevented, since the amide moiety forms a chelate with a lithium ion and $\mathrm{N}-2$ of the isoquinoline moiety, thus is kept away from $\mathrm{C}-8$ '. In contrast, we found in previous investigations on the synthesis of the pyridoacridone alkaloid demethyldeoxyamphimendine [21], that an ester group located at a comparable position (suitable for forming a chelate in cooperation with a pyridine nitrogen), can very well promote a directed remote metalation.

To test our hypothesis, we performed two more $\mathrm{D}_{2} \mathrm{O}$ quenching experiments with naphthalene analogues of esters $\mathbf{1 0}$ and amide

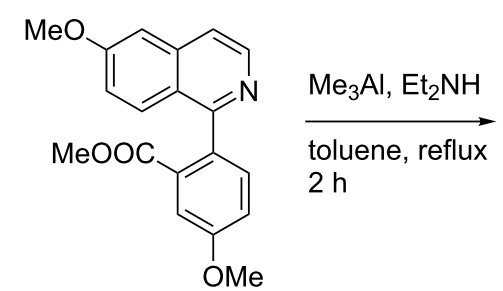

$10 \mathrm{c}$

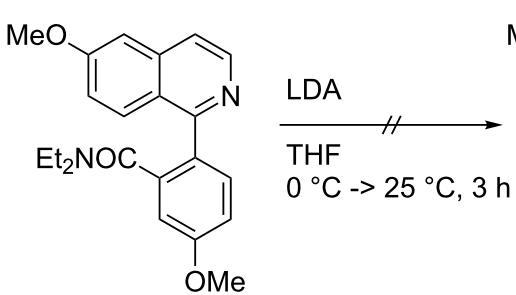

$12(31 \%)$<smiles>COc1ccc2cnc3ccc(OC)cc3c(=O)c2c1</smiles>

6

Scheme 5: Attempted synthesis of bianfugecine (6) via directed remote metalation and subsequent trapping of the carboxamide group.

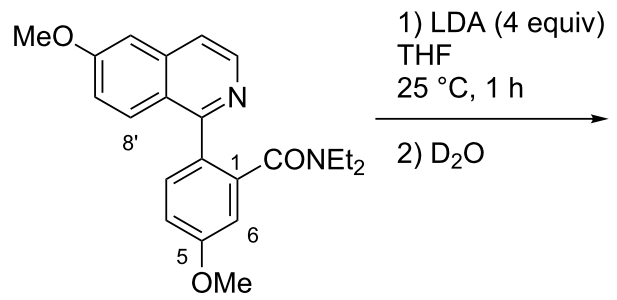

12<smiles>CCOC(=O)c1c(OC)cccc1-c1nccc2cc(OC)ccc12</smiles>

12-D

(about 40\%

D-incorporation) 
12. The methyl ester analogue $\mathbf{1 5}$ was obtained by Suzuki crosscoupling of naphthalene-1-boronic acid (13) and methyl 2-bromo-5-methoxybenzoate (14) in 68\% yield. Methyl ester $\mathbf{1 5}$ was converted into the corresponding diethyl amide $\mathbf{1 6}$ in 58\% yield by Weinreb amidation following the protocol described above for the synthesis of $\mathbf{1 2}$ (Scheme 7).

Incubation of methyl ester 15 with LDA ( 4 equiv LDA, $25^{\circ} \mathrm{C}$ ) over a period of $1 \mathrm{~h}$, followed by $\mathrm{D}_{2} \mathrm{O}$ quenching resulted in complete decomposition. In contrast, metalation of amide $\mathbf{1 6}$ under the same conditions and quenching with $\mathrm{D}_{2} \mathrm{O}$ led to the formation of the benzo[c]fluoren-7-one $\mathbf{1 7}$ in $38 \%$ yield. In recovered (about $20 \%$ ) educt $\mathbf{1 6}$, deuterium incorporation (about 20\%; calculated from integrals of the ${ }^{1} \mathrm{H}$ NMR spectrum) was exclusively observed at C- 6 of the benzamide moiety (Scheme 8). These data show no indication for a DreM at the peri-position C-8', since neither a 8'-deuterated arylnaphthalene nor a benzo[de]anthracen-7-one was detected. This observation is in accordance with results from the Snieckus group [36] on the remote metalation/cyclization of a 2-(1naphthyl)benzamide, which gave exclusively benzo[c]fluorenone (analogue of $\mathbf{1 7}$ lacking the methoxy group), and not the benzo[de $]$ anthracen-7-one. This clearly indicates that remote metalation, if any, occurs only in the ortho-position to the benzamide residue ( $\mathrm{C}-2$ of the naphthalene ring system), but not in the peri-position (C-8 of the naphthalene). Consequently, further attempts to initialize the cyclization of arylisoquinolines $10 \mathrm{c}$ and 12 to the oxoisoaporphine alkaloid bianfugecine (6, Scheme 5) by a DreM did not appear to be promising.

Finally, the alkaloids 6-O-demethylmenisporphine (4) and dauriporphinoline (5) were converted into their corresponding 6-methoxy derivatives, the oxoisoaporphine alkaloids menisporphine (2) and dauriporphine (3). Using Kunitomo's [7,17] protocol (methyl iodide in the presence of silver oxide), phenols $\mathbf{4}$ and $\mathbf{5}$ were converted into the alkaloids $\mathbf{2}$ and $\mathbf{3}$ in 33 and $49 \%$ yields (Scheme 9). In accordance to Kunitomo's observations, the isomeric methoxy compounds $\mathbf{1 8}$ and $\mathbf{1 9}$ were obtained as byproducts in significant yields (Scheme 9). In order to find a more convenient methylation protocol, we explored diazomethane, but no conversion was observed at all.

Finally, all of the synthesized alkaloids were tested for their cytotoxic potential in a MTT assay on the HL-60 cell line. Except for menisporphine (2) and bianfugecine (6, both $\mathrm{IC}_{50}$ values $\left.>50 \mu \mathrm{M}\right)$, all of the described oxoisoaporphine alkaloids and the isomers $\mathbf{1 8}$ and $\mathbf{1 9}$ showed significant cytotoxic activity. $\mathrm{IC}_{50}$ values of alkaloid 3 and of compounds 18 and 19 are ranging from $3-6 \mu \mathrm{M}$. Very strong cytotoxicity was determined for 6-O-demethylmenisporphine (4) with an $\mathrm{IC}_{50}$ value of $0.06 \mu \mathrm{M}$ and for dauriporphinoline (5) with $0.23 \mu \mathrm{M}$. So, at least in the HL-60 cell line, oxoisoaporphines

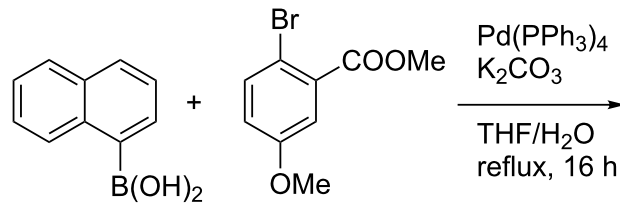

13<smiles>COc1ccc(-c2cccc3ccccc23)c(C(C)=O)c1</smiles>

$15(68 \%)$
$\mathrm{Me}_{3} \mathrm{Al}, \mathrm{Et}_{2} \mathrm{NH}$ toluene, reflux $2 \mathrm{~h}$<smiles>CCOCc1cc(OC)ccc1-c1cccc2ccccc12</smiles>

$16(58 \%)$

Scheme 7: Synthesis of 1-arylnaphthalene analogues 15 and 16.

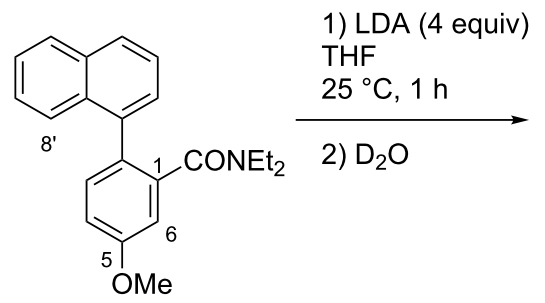

16

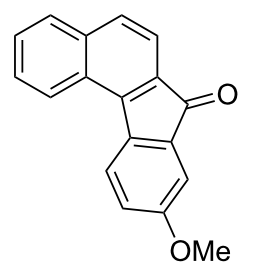

$17(38 \%)$<smiles>[2H]c1c(OC)ccc(-c2cccc3ccccc23)c1C(=O)OCC</smiles>

16-D

(about 20\%

D-incorporation)<smiles>COc1ccc2c(c1)C(=O)c1cccc3cccc-2c13</smiles>

benzo[de ]anthracen ${ }^{-7}$-one not observed 

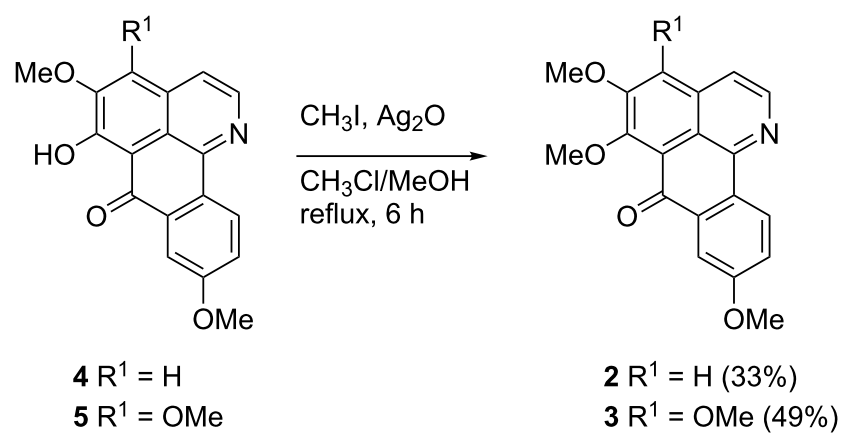<smiles>[R]C1=C(OC)C(=O)C2=C(OC)c3cc(OC)ccc3C2=C1</smiles>

$$
\begin{aligned}
18 R^{1} & =H(23 \%) \\
19 R^{1} & =\text { OMe }(29 \%)
\end{aligned}
$$

Scheme 9: Synthesis of the alkaloids menisporphine (2) and dauriporphine (3) by O-methylation of the alkaloids 6-O-demethylmenisporphine (4) and dauriporphinoline (5).

bearing a free hydroxy group at C-6 show outstanding cytotoxicity. These data are in accordance with previously reported results [37].

\section{Conclusion}

In conclusion, we worked out a novel approach for the synthesis of oxoisoaporphine alkaloids by direct ring metalation of alkoxy isoquinolines at $\mathrm{C}-1$, followed by the reaction with iodine as central step. Subsequent Suzuki cross-coupling to methyl 2-(isoquinolin-1-yl)benzoates and intramolecular acylation with Eaton's reagent afforded five alkaloids of the oxoisoaporphine type. Significant cytotoxicity was found for oxoisoaporphines bearing a free 6-hydroxy group.

\section{Experimental}

For experimental procedures and copies of ${ }^{1} \mathrm{H}$ and ${ }^{13} \mathrm{C}$ NMR spectra of all compounds see Supporting Information File 1.

\section{Supporting Information}

\section{Supporting Information File 1}

Experimental procedures and copies of ${ }^{1} \mathrm{H}$ and ${ }^{13} \mathrm{C}$ NMR spectra.

[http://www.beilstein-journals.org/bjoc/content/ supplementary/1860-5397-13-156-S1.pdf]

\section{References}

1. Hagel, J. M.; Facchini, P. J. Plant Cell Physiol. 2013, 54, 647-672. doi:10.1093/pcp/pct020

2. Shamma, M.; Guinaudeau, H. Nat. Prod. Rep. 1984, 1, 201-207. doi:10.1039/np9840100201

3. Stévigny, C.; Bailly, C.; Quetin-Leclercq, J. Curr. Med. Chem. - Anti-Cancer Agents 2005, 5, 173-182. doi:10.2174/1568011053174864

4. Kunitomo, J.; Satoh, M. Chem. Pharm. Bull. 1982, 30, 2659-2660. doi:10.1248/cpb.30.2659
5. Tang, H.; Wang, X.-D.; Wie, Y.-B.; Huang, S.-L.; Huang, Z.-S.; Tan, J.-H.; An, L.-K.; Wu, J.-Y.; Chan, A. S.-C.; Gu, L.-Q. Eur. J. Med. Chem. 2008, 43, 973-980. doi:10.1016/j.ejmech.2007.07.004

6. Castro-Castillo, V.; Suárez-Rozas, C.; Pabón, A.; Pérez, E. G.; Cassels, B. K.; Blair, S. Bioorg. Med. Chem. Lett. 2013, 23, 327-329. doi:10.1016/j.bmcl.2012.10.092

7. Kunitomo, J.; Satoh, M.; Shingu, T. Tetrahedron 1983, 39, 3261-3265. doi:10.1016/S0040-4020(01)91573-X

8. Okamoto, Y.; Tanaka, S.; Kitayama, K.; Isomoto, M.; Masaishi, M.; Yanagawa, H.; Kunitomo, J.-I. Yakugaku Zasshi 1971, 91, 684-687. doi:10.1248/yakushi1947.91.6_684

9. Kupchan, S. M.; Moniot, J. L.; Kanojia, R. M.; O'Brien, J. B. J. Org. Chem. 1971, 36, 2413-2418. doi:10.1021/jo00816a007

10. Kupchan, S. M.; O'Brien, P. F. J. Chem. Soc., Chem. Commun. 1973, 915-916. doi:10.1039/c39730000915

11. Castedo, L.; Saá, J. M.; Suau, R.; Villaverde, C. Heterocycles 1980, 14, 1131-1134. doi:10.3987/R-1980-08-1131

12. Kessar, S. V.; Gupta, Y. P.; Yadav, V. S.; Narula, M.; Mohammed, T. Tetrahedron Lett. 1980, 21, 3307-3308. doi:10.1016/S0040-4039(00)78675-8

13. Melzer, B.; Bracher, F. Org. Biomol. Chem. 2015, 13, 7664-7672. doi:10.1039/C5OB00926J

14. Orito, K.; Uchiito, S.; Satoh, Y.; Tatsuzawa, T.; Harada, R.; Tokuda, M. Org. Lett. 2000, 2, 307-310. doi:10.1021/01990360v

15. Cuny, G. D. Tetrahedron Lett. 2004, 45, 5167-5170. doi:10.1016/j.tetlet.2004.04.194

16. Chaudhary, S.; Pecic, S.; LeGendre, O.; Harding, W. W. Tetrahedron Lett. 2009, 50, 2437-2439. doi:10.1016/j.tetlet.2009.03.029

17. Kunitomo, J.; Kaede, S.; Satoh, M. Chem. Pharm. Bull. 1985, 33 , 2778-2782. doi:10.1248/cpb.33.2778

18. Jia, X.; Yang, D.; Zhang, S.; Cheng, J. Org. Lett. 2009, 11, 4716-4719. doi:10.1021/ol9017529

19. Chaitanya, M.; Yadagiri, D.; Anbarasan, P. Org. Lett. 2013, 15 , 4960-4963. doi:10.1021/ol402201c

20. Zhang, J.; Chen, J.; Zhang, X.; Lei, X. J. Org. Chem. 2014, 79 , 10682-10688. doi:10.1021/jo5020432

21. Melzer, B.; Plodek, A.; Bracher, F. J. Org. Chem. 2014, 79, 7239-7242. doi:10.1021/jo501312d

22. Kraskovskiy, A.; Kraskovskaya, V.; Knochel, P. Angew. Chem., Int. Ed. 2006, 45, 2958-2961. doi:10.1002/anie.200504024 
23. Metzger, A.; Schade, M. A.; Knochel, P. Org. Lett. 2008, 10, 1107-1110. doi:10.1021/ol7030697

24. Krätzschmar, F.; Kaßel, M.; Delony, D.; Breder, A. Chem. - Eur. J. 2015, 21, 7030-7034. doi:10.1002/chem.201406290

25. Plodek, A.; Raeder, S.; Bracher, F. Tetrahedron 2013, 69, 9857-9864. doi:10.1016/j.tet.2013.08.085

26. Bracher, F. Arch. Pharm. 1989, 322, 293-294. doi:10.1002/ardp.19893220511

27. Mink, K.; Bracher, F. Arch. Pharm. 2007, 340, 429-433. doi:10.1002/ardp.200700064

28. Dorow, R. L.; Herrinton, P. M.; Hohler, R. A.; Maloney, M. T.; Mauragis, M. A.; McGhee, W. E.; Moeslein, J. A.; Strohbach, J. W.; Veley, M. F. Org. Process Res. Dev. 2006, 10, 493-499. doi:10.1021/op050251y

29. Zewge, D.; Chen, C.-y.; Deer, C.; Dormer, P. G.; Hughes, D. L. J. Org. Chem. 2007, 72, 4276-4279. doi:10.1021/jo070181o

30. Kunitomo, J.-i.; Miyata, Y. Heterocycles 1986, 24, 437-440. doi:10.3987/R-1986-02-0437

31. MacNeil, S. L.; Gray, M.; Gusev, D. G.; Briggs, L. E.; Snieckus, V. J. Org. Chem. 2008, 73, 9710-9719. doi:10.1021/jo801856n

32. Levin, J. I.; Turos, E.; Weinreb, S. M. Synth. Commun. 1982, 12, 989-993. doi:10.1080/00397918208061938

33. Snieckus, V. Chem. Rev. 1990, 90, 879-933. doi:10.1021/cr00104a001

34. Tilly, D.; Magolan, J.; Mortier, J. Chem. - Eur. J. 2012, 18, 3804-3820. doi:10.1002/chem.201103920

35. Tilly, D.; Fu, J.-m.; Zhao, B.-p.; Alessi, M.; Castanet, A. S.; Snieckus, V.; Mortier, J. Org. Lett. 2010, 12, 68-71. doi:10.1021/ol902268h

36. Fu, J. M.; Zhao, B. P.; Sharp, M. J.; Snieckus, V. J. Org. Chem. 1991, 56, 1683-1685. doi:10.1021/jo00005a004

37. Cheng, J.-J.; Tsai, T.-H.; Lin, L.-C. Planta Med. 2012, 78, 1873-1877. doi:10.1055/s-0032-1327785

\section{License and Terms}

This is an Open Access article under the terms of the Creative Commons Attribution License (http://creativecommons.org/licenses/by/4.0), which permits unrestricted use, distribution, and reproduction in any medium, provided the original work is properly cited.

The license is subject to the Beilstein Journal of Organic Chemistry terms and conditions:

(http://www.beilstein-journals.org/bjoc)

The definitive version of this article is the electronic one which can be found at: $\underline{\text { doi:10.3762/bjoc. } 13.156}$ 